\title{
Attenuation characteristics, source parameters and site effects from inversion of $S$ waves of the March 31, 2006 Silakhor aftershocks in Western Iran
}

\author{
Somayeh Ahmadzadeh ${ }^{1}$, Stefano Parolai ${ }^{2,3}$, Gholam Javan-Doloei ${ }^{*}, 1$, Adrien Oth ${ }^{4}$ \\ ${ }^{1}$ International Institute of Earthquake Engineering and Seismology, Tehran, Iran \\ ${ }^{2}$ Helmholtz Centre Potsdam, GFZ German Research Centre for Geosciences, Potsdam, Germany \\ ${ }^{3}$ Now at: Istituto Nazionale di Oceanografia e di Geofisica, Sperimentale - OGS, Sgonico (TS), Italy \\ ${ }^{4}$ European Center for Geodynamics and Seismology, Luxemburg
}

Article history

Received August 15, 2017; accepted October 30, 2017.

Subject classification:

Generalized Inversion Technique; Source parameter; Site response; Bootstrap analysis; Zagros.

\begin{abstract}
A nonparametric generalized inversion technique (GIT) has been used to derive attenuation characteristics, source parameters and site amplification effects from $S$ wave spectra of the 2006 Silakhor earthquake aftershocks recorded at 10 temporary stations in the epicentral area of the main shock along the main recent fault in Zagros region. We apply a total number of 971 spectral amplitudes from 213 aftershocks with $M_{L} 1.5-4.4$ in the frequency range $0.5-35 \mathrm{~Hz}$. The obtained nonparametric attenuation curves decay monotonically with distance for the entire frequency range and the estimated $S$ wave quality factor shows low $Q$ values with fairly strong frequency dependence. We fit the omegasquare source model to the inverted source spectra to derive earthquake source parameters. The estimated stress drops range from 0.04 to $5.3 \mathrm{MPa}$ with an average of $0.9 \mathrm{MPa}$, within the range typically observed for crustal earthquakes in other regions of the World. The evaluated apparent stresses vary from 0.009 to $0.9 \mathrm{MPa}$ and its relation with stress drops is generally consistent with the theoretically expected relation assuming Brune model. The local magnitude $M_{L}$ shows a linear correlation with the moment magnitude $M_{W}$ that underestimates the $M_{W}$ scale by about 0.1-0.5 magnitude units for $M_{W}$ 1.5-3.0. We found a gradual increase in corner frequency values against seismic moments that may be considered as an evidence for a deviation from self-similarity scaling though the magnitude range of this study is fairly small to deduce a firm conclusion. The comparison of estimated GIT site amplification functions with the evaluated horizontal to vertical $(H / V)$ spectral ratios shows different levels of amplification in site responses due to amplification of the vertical component; however, the overall shape of site spectra provided by both methods are relatively similar.
\end{abstract}

\section{Introduction}

The Iranian plateau among the Alpine-Himalayan seismic belt is limited between the convergent movements of the Arabian plate in the southwest and the Eurasian plate in the northeast. This convergence makes Iran one of the most seismically active areas of the World. Iran has been frequently shaken by great earthquakes accompanied with heavy casualties and economic losses. The Zagros fold - thrust belt, known as one of the youngest and most active continental collision zones on earth, is the result of the continued convergence between Arabia and Eurasia plates [Snyder and Barazangi 1986]. Therefore, the Zagros region can be considered as one of the major active seismotectonic provinces with frequent and large earthquakes. The Main Recent fault (MRF) is an important element of tectonic units defined within the Zagros composed of a series of right-lateral strikeslip faults. Earthquakes occurring on or near the MRF have larger magnitudes than those in the other parts of the Zagros region. Also, the mechanism of earthquakes and seismic potential of the MRF is quite different from those earthquakes occurring within the rest of the Zagros range. The most devastating earthquake of the region, the 1909 January 23 Silakhor earthquake $\left(m_{b} 7.4\right)$, occurred on the Main Recent fault and produced over $40 \mathrm{~km}$ surface rupture [Tchalenko and Braud 1974]. Based on the report of Ambraseys and Melville [1982], this historical event was strongly felt in a large area with more than 100 damaged villages and more than 6000 fatalities.

The latest large event along the main recent fault (MRF), the Silakhor earthquake of 31 March 2006 with $\mathrm{M}_{\mathrm{L}} 6.1$ (IIEES), occurred in the Silakhor plain in 
the south of Broujerd city in the Lorestan province in west Iran. A hypocentral depth ranging between 6 and $14 \mathrm{~km}$ was reported by several agencies [Peyret et al. 2008, Ghods et al. 2012]. According to field investigations no significant surface rupture was observed and a maximum intensity of VIII was reported by Moghadam et al. [2006]. This event severely affected about 300 villages in the Silakhor plain with 68 fatalities and more than 1400 injuries. The 2006 Silakhor earthquake was preceded by two fairly large foreshocks with magnitudes of 4.6 and 5.2, respectively, and followed by a large number of aftershocks. The occurrence of two relatively large foreshocks effectively alarmed many people to leave their homes leading to a lower number of casualties than expected.

Earthquake ground shaking at a specified location depends on three main region-specific parameters including seismic-source, wave propagation parameters and seismic-site effects. The study of these region-specific parameters is required to predict accurate ground-motion amplitudes in order to enable reliable seismic hazard assessment.

The source, path and site effects can be separated from each other in the Fourier amplitude spectra (FAS) of recorded ground motion by implementing the common generalized inversion technique (GIT). This method was firstly proposed by Andrews [1986] recasting the spectral ratios method into a generalized inverse problem, then decomposing the body-wave spectra into source, site, and path contributions, simultaneously. Several authors have used and developed this approach to earthquake ground-motion data worldwide [Castro et al. 1990, Boatwright et al. 1991, Hartzell 1992, Parolai et al. 2000, Salazar et al. 2007 among others]. For instance, Castro et al. [1990] introduced a two-step nonparametric inversion method to isolate source, site and path effects along the Guerrero, Mexico, subduction zone.

In recent years, a few studies have been conducted to investigate seismic-source and wave propagation parameters in various regions of the Iranian plateau. Among these, however, only a limited number are related to the Zagros region. Zafarani and Hassani [2013] applied the GIT to 148 S-wave amplitude spectra of 35 events recorded at 40 stations of the Iranian strong-motion network, which have been installed by the Building and House Research Center (BHRC). Source parameters and site response of Swaves in two parts of the Zagros region were examined for the events in the magnitude range from 4.2 to 6.2. Rahimi et al. [2008] estimated the coda Q, Qc, for the Zagros zone by analyzing the coda waves of
51 local earthquakes recorded on three stations of the Iranian National Seismic Network (INSN) with magnitudes ranged from 3.1 to 4.9 during March and April 2006.Most of the analyzed events were foreshocks and aftershocks of the 2006 Silakhor earthquake. Using the $\mathrm{SH}$-wave acceleration spectral data, Hamzehloo et al. [2010] estimated the source parameters and frequency dependent shear wave quality factor of the 2006 Silakhor earthquake and only one of its foreshocks and one aftershock that were recorded at 8 stations.

In our study, we applied the nonparametric GIT to a large number of 2006 Silakhor earthquake aftershocks, with a dataset composed of 971 records from 213 events, to evaluate source, site and path effects, simultaneously in the epicentral area of Silakhor earthquake. The obtained nonparametric attenuation functions are parameterized to obtain an estimate of the $S$-wave frequency-dependent quality factor and the results are compared with other studies. The evaluated source spectra are interpreted using the omegasquare Brune [1970] model to retrieve seismic moments and stress drop values. Finally, we compare and discuss the site response functions estimated from GIT with those from horizontal-to-vertical (H/V) spectral ratios.

\section{Database}

On 31 March 2006, the $M_{L} 6.1$ (IIEES) Silakhor earthquake occurred along the Zagros main recent fault (MRF) in the Lorestan province, west Iran. The earthquake was followed by a large number of aftershocks. Most of them were recorded by a local temporary seismic network including 10 short-period stations that was deployed around the epicenter of the main shock, 5 days after the mainshock for about 2 months from 5 April to 10 June 2006. The network consisted of five three component short-period Guralp CMG-6TD seismometers and five Guralp CMG5TD accelerometers with a sampling rate of $100 \mathrm{~Hz}$. More than 1300 aftershocks were recorded during network installation. The local magnitudes of these events were determined using SEISAN software [Havskov and Ottemöller 1999]. We relocated events using the velocity model for the region [Sepahvand et al. 2012] and selected a subset of 213 events with wellconstrained locations (location error $<3 \mathrm{~km}$ and GAP $<180^{\circ}$ ) with $\mathrm{M}_{\mathrm{L}}>1.5$ (Figure 1). Each of the selected events is recorded by at least three stations and each of the used stations recorded at least three events. The final database is composed of 971 records from 213 earthquakes with a magnitude in range of $M_{L}$ 1.5-4.4 and hypocentral distances ranging from $3 \mathrm{~km}$ to 41 


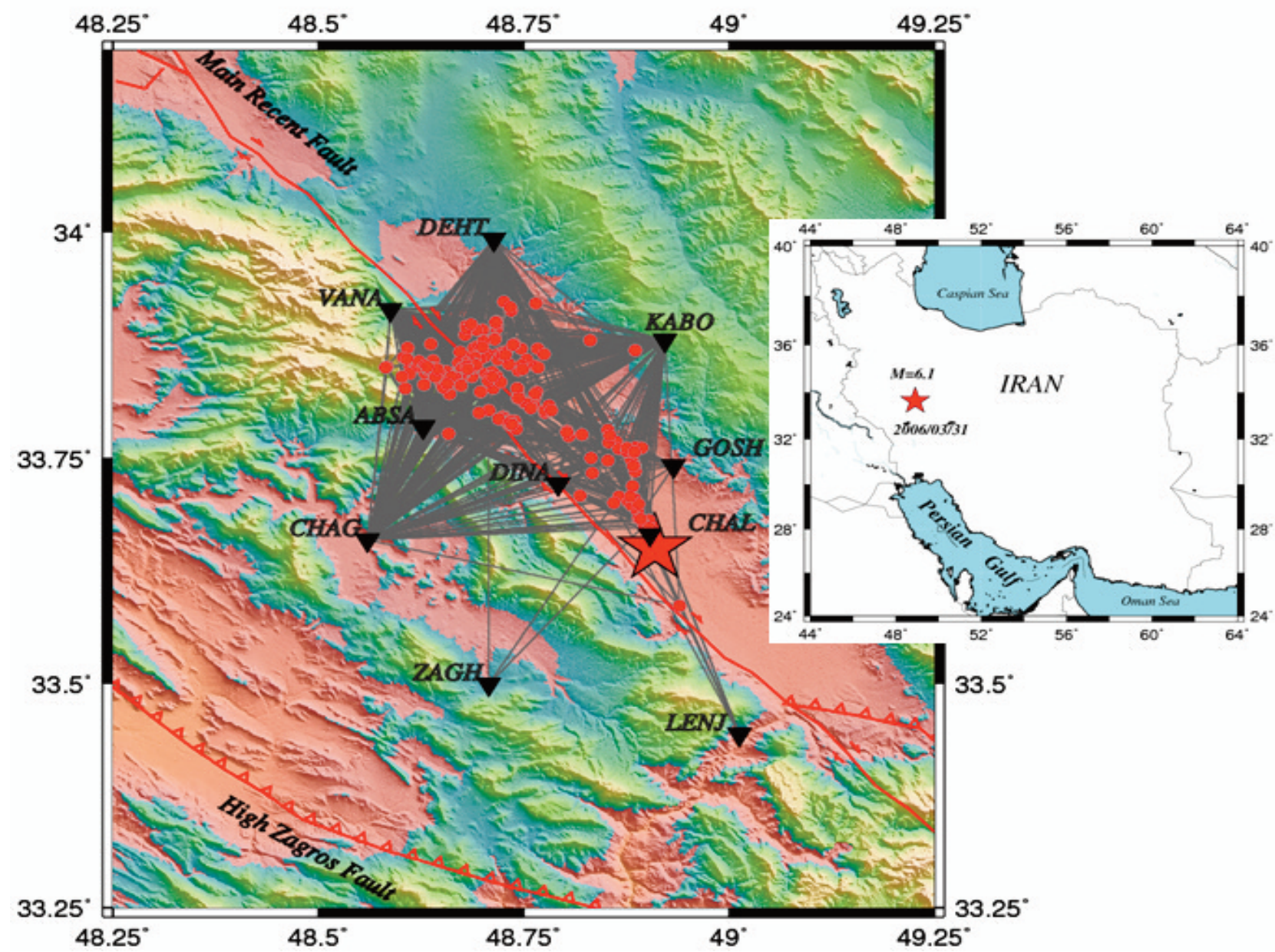

Figure 1. Epicenters of 2006 Silakhor earthquake (star) and aftershocks (circles). Inverse triangles indicate the location of 10 stations installed around the epicenter of the main shock. The source-station ray paths are shown as gray lines.
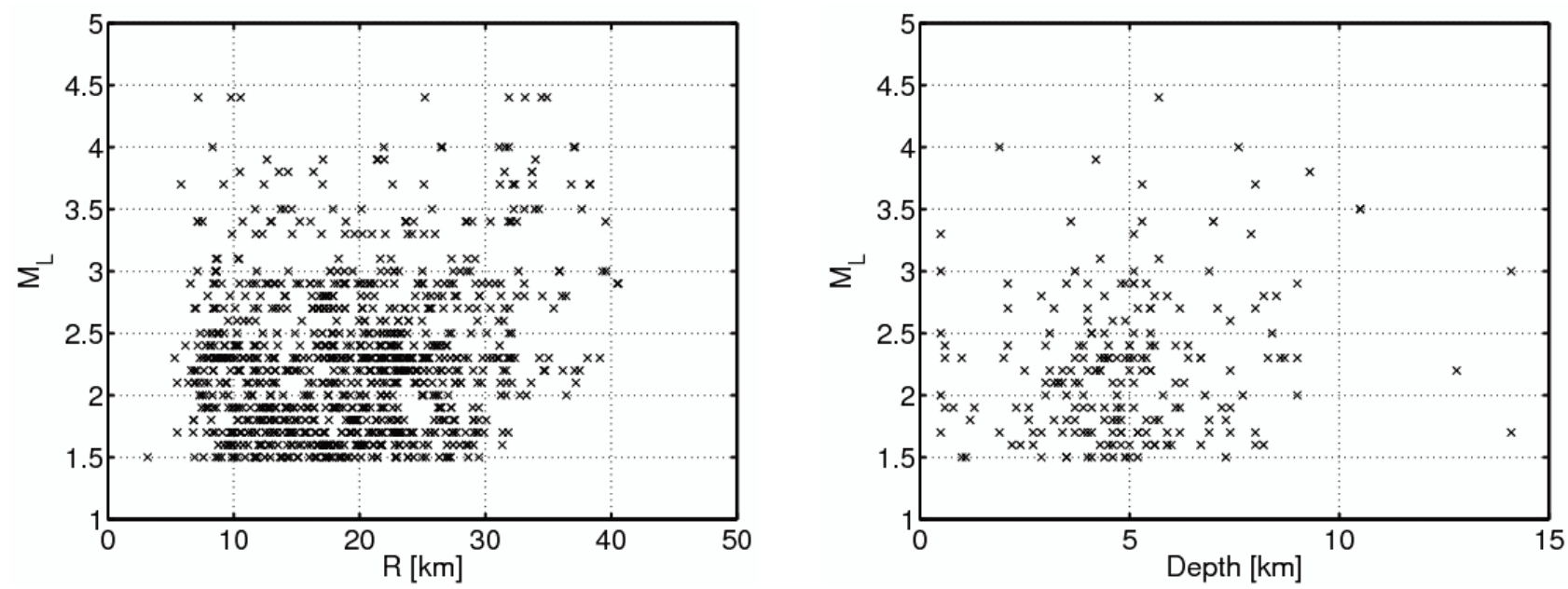

Figure 2. Distribution of earthquake magnitude $\left(\mathrm{M}_{\mathrm{L}}\right)$ versus hypocentral distance (left) and depth (right).

$\mathrm{km}$. Figure 1 shows the location of 2006 Silakhor mainshock and 213 selected aftershocks as well as temporary local stations around the Zagros Main Recent Fault with the source-station travel paths. The distribution of data in terms of magnitude versus hypocentral distance and focal depth is presented in Figure 2. The dataset spans the range of $\mathrm{M}_{\mathrm{L}}=1.5-4.4$ with focal depths ranging between $0.5-14 \mathrm{~km}$. The majority of our events have magnitudes in the range 1.5 to 3 and the smallest hypocentral distance in the dataset is $3 \mathrm{~km}$. Since near-field terms normally become most important at distances shorter than a few source dimensions, this effect is not expected to considerably affect the analysis. 

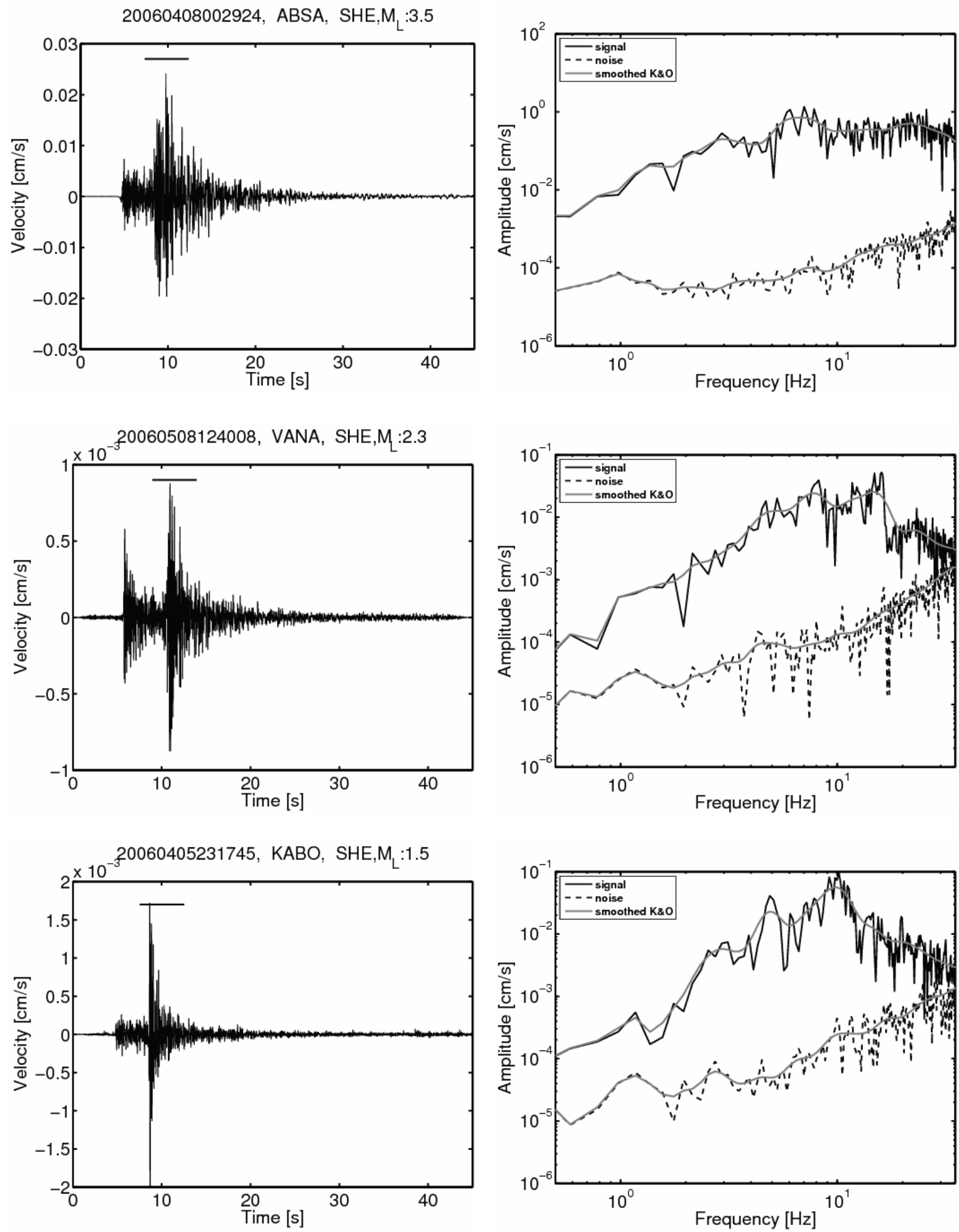

Figure 3. Three instrument-corrected EW component velocity seismograms at stations ABSA, VANA and KABO (left) and calculated acceleration FAS of the seismograms (right). The smoothed FAS using the Konno-Ohmachi window with $b=20$ are indicated with gray lines for both signal and noise spectra.

For the spectral analysis, the raw recordings were corrected for instrument response and a time window of 5 seconds length was selected on the horizontal components starting 1 second before the S-wave ar- rival. Each selected window is cosine-tapered (5\%) and the acceleration Fourier amplitude spectra (FAS) have been calculated. To compute the signal-to-noise ratio (SNR), a pre-event noise windows with the same 
length as the $S$-wave windows were considered (for some events the available pre-P noise were less than 5 seconds) and only records with a SNR larger than 3 at each frequency in the selected frequency range was taken into account for the present research.

The selected frequency range of this study is limited to $0.5-35 \mathrm{~Hz}$, due to the signal-to-noise ratio (SNR) constraint. The obtained amplitude spectra were smoothed using the Konno and Ohmachi [1998] windowing function with $b=20$ and sampled at 40 frequency points equidistant on log scale between 0.5 and $35 \mathrm{~Hz}$. The root-mean-square average of the two horizontal components was considered in the analysis. The above data processing procedures are shown in Figure 3 for three examples.

\section{Generalized Inversion Technique}

The generalized inversion technique (GIT) has been widely used to retrieve the source spectra, attenuation characteristics and site effects in many regions of the world [e.g. Castro et al. 1990, 1996; Dutta et al. 2003; Oth et al. 2011]. Here we provide a brief description of the GIT method and refer the reader to the above-mentioned papers for more in-depth details of this technique.

The observed Fourier amplitude spectrum (FAS) of the ground motion can be expressed as multiplication of the following three terms in frequency domain:

$$
U_{i j}\left(f, M_{i}, R_{i j}\right)=S_{i}\left(f, M_{i}\right) \cdot A\left(f, R_{i j}\right) \cdot G_{j}(f)
$$

where $U_{i j}\left(f, M_{i}, R_{i j}\right)$ is the observed FAS at site $\mathrm{j}$ from source $i$ with magnitude $M_{i} ; R_{i j}$ is the hypocentral distance; $S_{i}\left(f, M_{i}\right)$ represents the source spectrum of the ith event; $A\left(f, R_{i j}\right)$ denotes the attenuation along the travel path, and $G_{j}(f)$ is the site amplification function of the jth station. By taking the logarithm, the above Equation can be linearized as Equation 2:

$\log _{10} U_{i j}\left(f, M_{i}, R_{i j}\right)=\log _{10} S_{i}\left(f, M_{i}\right)+\log _{10} A\left(f, R_{i j}\right)+\log _{10} G_{j}(f)$

Equation (2) provides a system of linear equations of the form $A x=b$, with data vector $b$ including the observed spectral amplitudes, model vector $\mathrm{x}$ and system matrix A. This system of equations can be solved in a least squares sense for each frequency using appropriate inversion algorithms [e.g. SVD and LSQR] [Andrews 1986, Menke 1989]. According to Andrews [1986] one undetermined degree of freedom exists in Equation (2) that can be resolved by assuming a predefined source spectral model [Boatwright et al. 1991, Salazar et al. 2007] or setting the site response of one or more rock sites in the dataset equal to one [Andrews 1986, Castro et al. 1990, Parolai et al. 2000].

Following Castro et al. [1990] the inversion can be implemented using either a parametric or nonparametric approach. In parametric scheme [e.g. Salazar et al. 2007] a predefined function is considered for attenuation along the travel path while in the nonparametric approach [e.g. Oth et al. 2009] the attenuation is constrained to be a smooth function of distance including all attenuation effects like anelastic attenuation or geometrical spreading that takes the value of 1 at the reference distance R0, which is set to $9 \mathrm{~km}$ in present work.

We solve the linear system of equations in one step implementing the LSQR algorithm [Paige and Saunders 1982] to determine the source spectra, site responses, and attenuation characteristics, simultaneously. To eliminate the undetermined degree of freedom [Andrews 1986], one or several appropriate sites can be considered as a reference condition by setting either the amplification of one station or the average of several stations to be approximately one, irrespective of frequency. In order to select an appropriate reference condition, the $\mathrm{H} / \mathrm{V}$ spectral ratio and geological setting of all stations as well as the results of trial runs using various reference conditions have been considered.

The H/V spectral ratio calculated from the amplitude spectra at two GOSH and VANA stations are almost flat and close to unity (Figure 4). On the other hand, these two stations are located on the rock outcrop based on field observations.

For these reasons, in addition to the results of trial runs leading to reasonable spectral shapes of the source and site terms in the inversion, we conclude that selecting stations GOSH and VANA as reference stations and setting the average of site responses at these two stations to be equal to one is the most appropriate choice for this study. It is noteworthy that all site amplification and source spectra derived in the inversion are relative to the selected reference sites.

The bootstrap method [Efron 1979)] is applied in order to evaluate the stability of inversion results following Parolai et al. [2000, 2004]. In this method, a new dataset is obtained by means of randomly selecting each row from the original system matrix with the same size. A certain row can either be selected several times or never.

Repeated inversions of the bootstrap data set are performed at each frequency and then the means and standard deviations of these bootstrap samples assessed. We carried out 100 bootstrap inversions and 

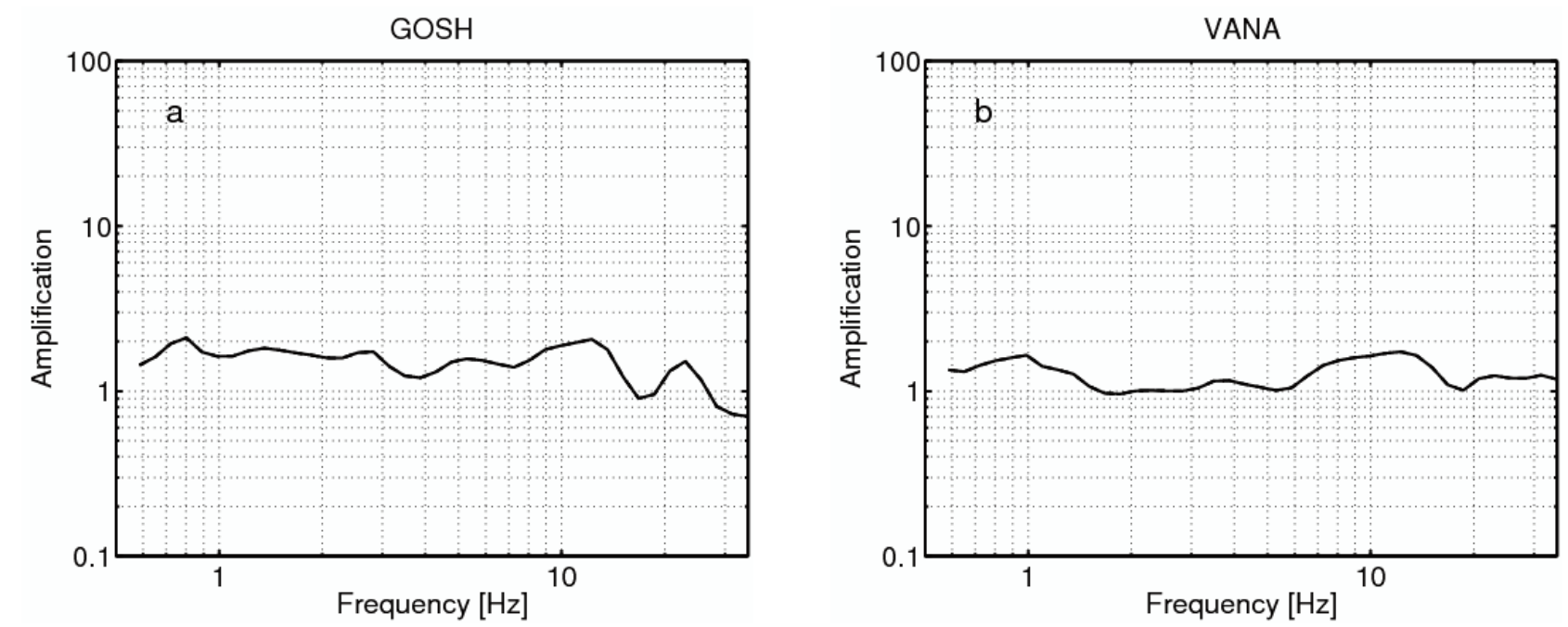

Figure 4. The H/V spectral ratio calculated from the amplitude spectra at station GOSH (a) and VANA (b). The spectral ratios are almost flat and near to one.

calculated the mean and standard deviation of these 100 iterations for each model parameter.

\section{Inversion results}

\subsection{Attenuation Characteristics}

Applying a one-step GIT inversion to the selected spectral amplitudes, the nonparametric attenuation functions are determined. The hypocentral distance ranging from $3 \mathrm{~km}$ to $41 \mathrm{~km}$ is divided into 13 bins of 3 $\mathrm{km}$ width. We acknowledge that with this limited distance range available in the dataset, only limited conclusions can be drawn on the overall attenuation characteristics and in particular its frequency dependence.

Nonetheless, as shown below, the attenuation curves are robust and the data coverage within the limited distance range is excellent.

The obtained attenuation functions for two

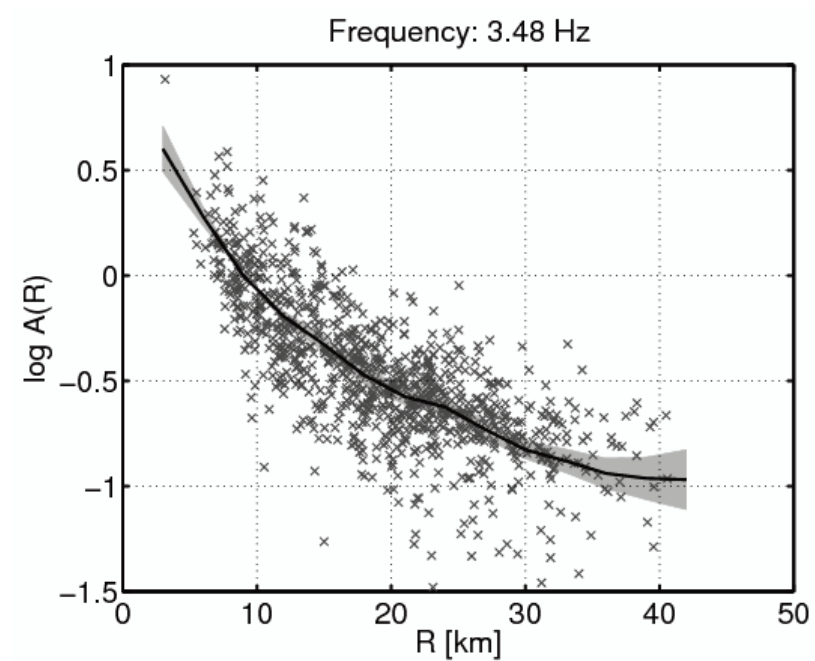

selected frequencies together with the observed amplitudes corrected for source and site terms are shown in Figure 5. The curves decay monotonically with distance and the observed data points are fairly described by the calculated attenuation curves.

The attenuation functions for all 40 frequency points selected for the analysis between $0.5 \mathrm{~Hz}$ and 35 $\mathrm{Hz}$ are displayed in Figure 6. A 1/ $\mathrm{R}$ decay function is also indicated for comparison. As we set the reference distance to $9 \mathrm{~km}$, the attenuation function takes the value $\log A(f, R)=0$ at $9 \mathrm{~km}$.

In general, the curves show a simple shape consistently decreasing with distance almost for the entire frequency range with a more rapid decay for the high frequency attenuation curves than the low frequency ones, as expected. The low frequency curves decay similarly to a $1 / \mathrm{R}$ function up to about $20 \mathrm{Km}$ whereas at larger distances the curves attenuate more quickly than $1 / R$ for the entire frequency band.

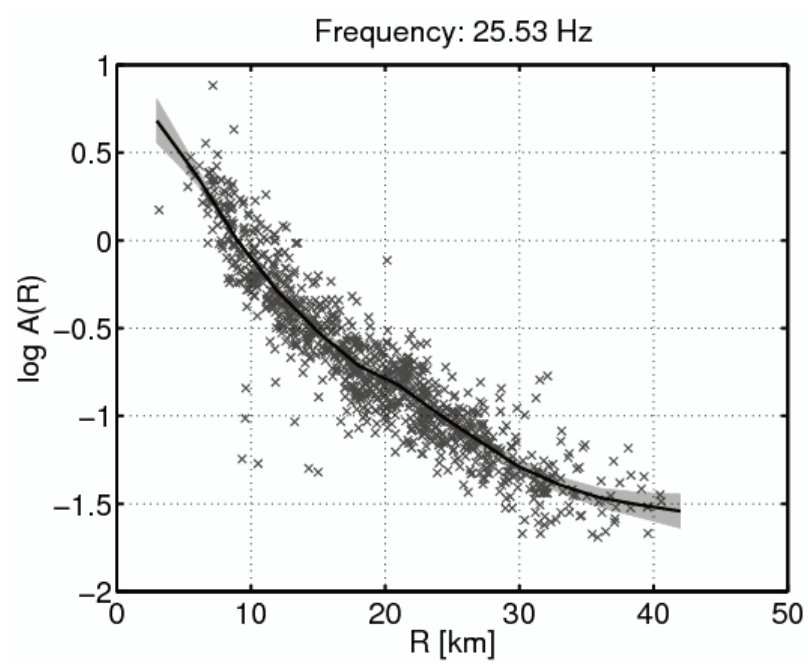

Figure 5. Nonparametric attenuation functions for two selected frequencies. The gray shaded area denotes one standard deviation calculated by bootstrap analysis around the mean. The observed spectral amplitudes corrected for source and site terms are indicated as gray crosses. 
The obtained nonparametric attenuation term contains all attenuation characteristics including apparent quality factor and geometrical spreading. Assuming a simple geometrical spreading model, the apparent quality factor can be estimated through fitting the following equation to the attenuation function:

$$
A(f, R)=\frac{C}{R^{b}} \exp \left[-\frac{\pi f(R-C)}{Q(f) v_{S}}\right]
$$

where $\mathrm{R}$ is the hypocentral distance in $\mathrm{km}, \mathrm{C}$ is the reference distance for the fit, $Q(f)$ denotes the apparent $S$ wave quality factor, $\mathrm{v}_{\mathrm{S}}$ is the shear-wave velocity and $\mathrm{b}$ is the geometrical spreading exponent. Due to the existing trade off in estimation of $\mathrm{b}$ and $\mathrm{Q}(\mathrm{f})$ together, we set the $b=1$ and restrict our calculation to the definition of $Q(f)$. The nonparametric attenuation function, $A(f, R)$ is corrected for the geometrical spreading $(G(r)=C / R)$ and then the frequency dependent quality factor is evaluated from the slope of a least squares regression to $\log A(f, r)$ $\log G(r)$ versus distance. We fit a power function of the form $Q(f)=Q_{0} f^{N}$ to the obtained $Q(f)$ values through a least square fit to determine $\mathrm{Q}_{0}$ and N. As shown in Figure 7 , the frequency dependent quality factor is approximated with the relation:

$$
Q(f)=35.99 f^{0.77}
$$

The defined apparent quality factor with $\mathrm{N}=0.77$ demonstrates fairly strong frequency dependence in our studied area located in Zagros region. This evaluated apparent $\mathrm{Q}$ factor with low $\mathrm{Q}_{0}$ and value of $\mathrm{N}$ near to 1 indicates high attenuation characteristics in this region and is similar to the results have been found for other tectonically active regions of Iran and the world [Rovelli

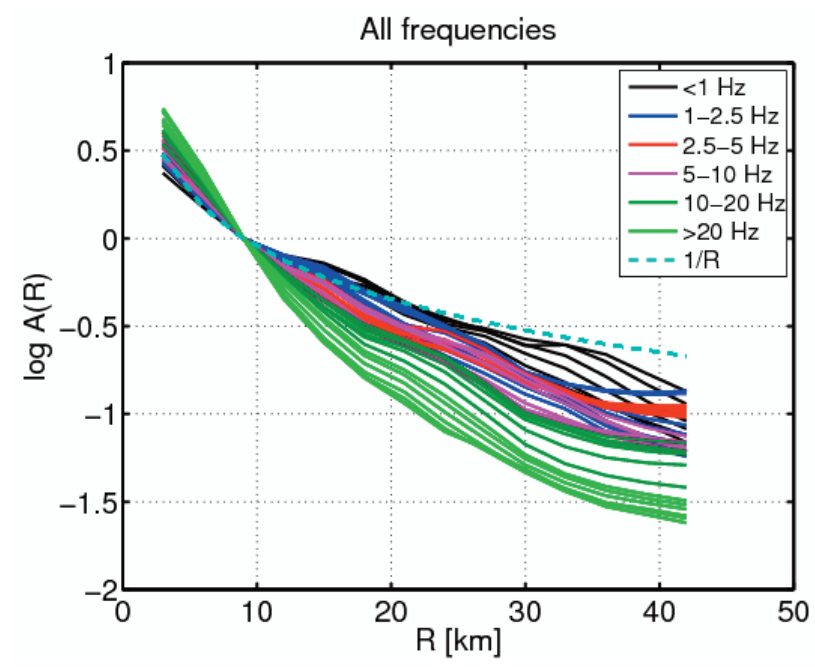

Figure 6. Nonparametric attenuation functions versus hypocentral distance for all frequencies. For comparison, a $1 / \mathrm{R}$ curve is depicted as a dashed line. Note that $\log A(f, R)=0$ at the reference distance $\mathrm{R}_{0}=9 \mathrm{~km}$.

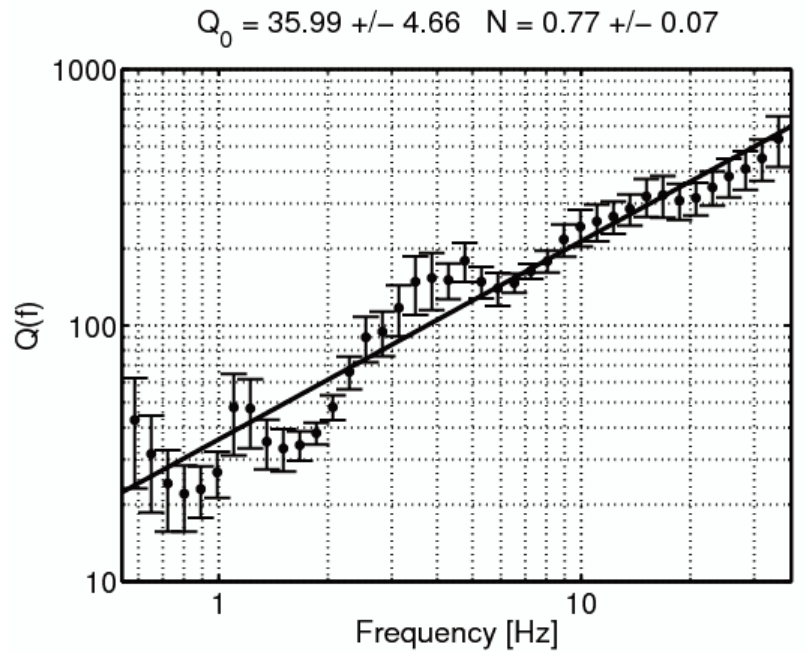

Figure 7. Solid black line indicates the obtained apparent $\mathrm{Q}(\mathrm{f})$ model from the analysis of the attenuation functions shown in Figure 6. The individual $Q$ values derived at each given frequency are denoted by dots and error bars.

1982, Hellweg et al. 1995, Yoshimoto et al. 1993, Castro et al. 1996, Bindi et al. 2006, Motazedian 2006 amongst others].

It is important to point out that due to the tradeoff between $\mathrm{Q}$ and the geometrical spreading function, we discuss $\mathrm{Q}$ in the framework of the simplified geometrical spreading model adopted here. In addition since the nonparametric attenuation function $(A(f, r))$ includes all effects leading to attenuation of seismic waves along the travel path, the apparent quality factor obtained by fitting Equation (3) to the attenuation curves include both intrinsic and scattering attenuation. However obtained apparent quality factor is frequency dependent, we cannot definitely conclude that the intrinsic $\mathrm{Q}$ is also frequency dependent.

\subsection{Source Spectra}

We fit the $\omega^{2}$ source model [Brune 1970, 1971] to the inverted nonparametric source spectra in order to retrieve earthquake source parameters including corner frequency, $f_{C}$ and seismic moment, $\mathrm{M}_{0}$. The acceleration source spectra in terms of the $\omega^{2}$ model can be expressed by:

$$
S(f)=(2 \pi f)^{2} \frac{R^{\theta \varphi} V F}{4 \pi \rho v_{S}^{3} R_{0}} M(f)
$$

and

$$
M(f)=\frac{M_{0}}{1+\left(f / f_{C}\right)^{2}}
$$

where $R^{\theta \phi}$ is the average shear wave radiation pattern, $V=1 / \sqrt{ } 2$ accounts for the division of $S$-wave energy into two horizontal components, $\mathrm{F}=2$ is free sur- 
face amplification, $\rho=2.8 \mathrm{~g} / \mathrm{cm}^{3}$ and $V_{S}=3.4 \mathrm{~km} / \mathrm{s}$ are density and shear wave velocity estimates in the vicinity of source region, respectively, $\mathrm{R}_{0}$ denotes the reference distance, and $\mathrm{M}(f)$ represents the moment rate spectrum.

Figure 8 shows four examples of inverted source spectra (solid black lines, with standard deviation as gray shading) along with an $\omega^{2}$ source model fitted to the spectra (dashed lines) using non-linear least squares. Estimated corner frequencies and seismic moments are defined by this fitting procedure. Taking into account the standard deviations obtained from 100 bootstrap analyses, the evaluated source spectra are generally very stable and the spectra are appropriately fitted by $\omega^{2}$ model.

Under the assumption of the $\omega^{2}$ model the acceleration spectra increase as $\mathrm{f}^{2}$ at low frequencies with a plateau at high frequencies. Generally, the observed acceleration Fourier spectra show a decay at high frequencies above a certain frequency which is character-

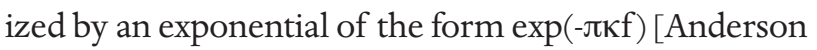
and Hough 1984]. The high-frequency spectral decay $(\kappa)$

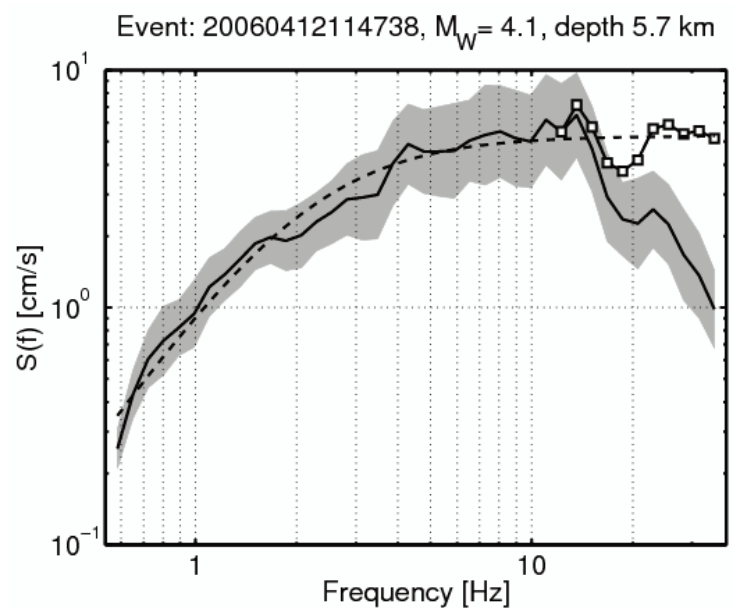

Event: $20060531224612, \mathrm{M}_{\mathrm{W}}=2.7$, depth $4.6 \mathrm{~km}$

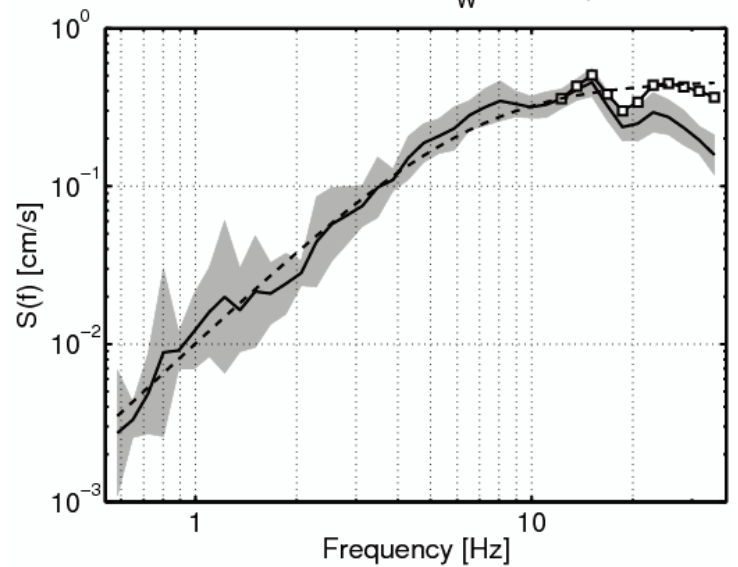

is often considered as a site effect originating from near surface attenuation [Hanks 1982, Anderson and Hough 1984] or a source related parameter [Papageorgiou and Aki 1983]. Since we did not consider this high-frequency $\kappa$ decay term in the reference site constraint (stations GOSH and VANA), it can be reasonably expected to shift into the estimated source spectra as indicated by Oth et al. [2011]. In order to evaluate the influence of the exponential $\kappa$ term on the source spectra we fitted equation (7) to the high-frequency part of the spectra to estimate the $\kappa$ values Oth et al. [2011] as follows

$$
\log _{10} S_{i}\left(f>f_{E}\right)=S_{0, i}-\left(\log _{10} e\right) \cdot \pi f \kappa_{i}
$$

where $f_{\mathrm{E}}$ is the lower frequency limit.

Taking into account the magnitude range of the events, we set $\mathrm{f}_{\mathrm{E}}=12 \mathrm{~Hz}$ (we checked results from applying both $\mathrm{f}_{\mathrm{E}}=12$ and $\mathrm{f}_{\mathrm{E}}=15 \mathrm{~Hz}$ without remarkable differences) to be adequately above the corner frequency range of the events [Parolai and Bindi 2004] to obtain reliable $\kappa$ estimates, however essentially $f_{E}$ would have to be properly selected for each individual spectrum.
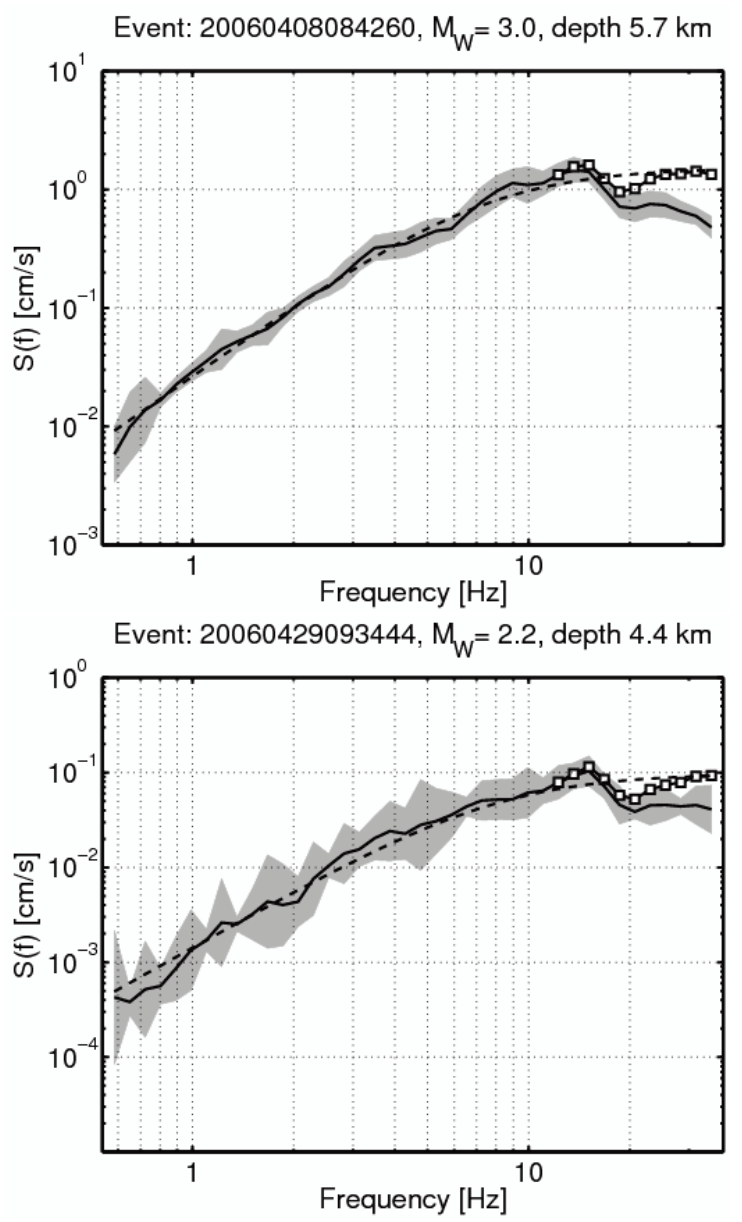

Figure 8. Examples of acceleration source spectra derived from GIT inversion (solid black lines) with related standard deviation (shaded area) of four events. The best fitted $\omega^{2}$ model is represented by dashed lines. The white squares trend indicates the high frequency $\kappa$ correction at frequencies larger than $12 \mathrm{~Hz}$. 
The distribution of $\kappa$ values is depicted in Figure 9. The obtained values are normally distributed and very small, with the mean value of $0.011 \mathrm{~s}$. These small $\kappa$ values indicate the attenuation corrected spectra are subjected to relatively slight high frequency diminution effect. To investigate how these $\kappa$ values affect the source spectra, the spectra have been corrected for $\kappa$ decay for frequencies larger than $12 \mathrm{~Hz}$ (indicated with white squares at high frequencies in Figure 8). As can be seen from the Figure 8, the $\kappa$ effect slightly affects the high frequency part of source spectra in our dataset.

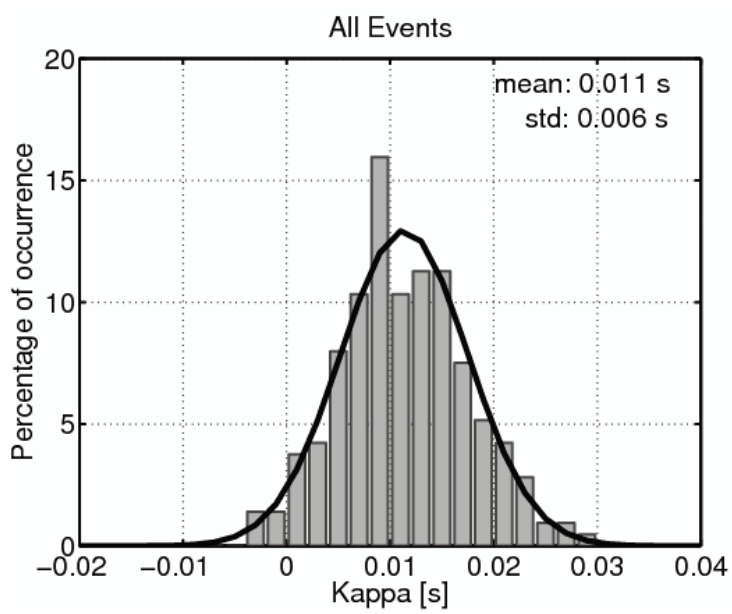

Figure 9. Distribution of the estimated $\kappa$ values evaluated from the high-frequency part of the inverted source spectra for $\mathrm{f}>12$ $\mathrm{Hz}$. The obtained $\kappa$ values have approximately normal distribution.

We determine the stress drop values based on the estimated $M_{0}$ and $f_{C}$ values using the following relations [Brune 1970, 1971]:

$$
\begin{array}{r}
r=\frac{2.34 v_{S}}{2 \pi f_{C}} \\
\Delta \sigma=\frac{7 M_{0}}{16 r^{3}}
\end{array}
$$

Moreover, we compute the apparent stress $\left(\sigma_{\mathrm{a}}\right)$ for each event as follows:

$$
\sigma_{a}=\mu \frac{E_{S}}{M_{0}}
$$

where $\mu$ is the rigidity modulus $\left(\mu=v_{s}^{2} \cdot \rho\right)$ and $E_{s}$ is the radiated $S$-wave energy that can be calculated from the inverted source spectra using the relation [e.g. Izutani and Kanamori 2001]:

$$
E_{S}=\frac{4 \pi}{5 \rho v_{S}} \int_{0}^{\infty}|f M(f)|^{2} d f
$$

Figure 10a represents the evaluated corner frequency versus seismic moment with the corresponding standard deviations indicated as horizontal and vertical error bars, respectively. Dashed lines represent constant stress drop values from 0.01 to $10 \mathrm{MPa}$. The inferred corner frequencies range vary from 1.7 to 17 $\mathrm{Hz}$ whereas the seismic moments vary within 4 orders of magnitude, from $10^{\wedge} 11 \mathrm{Nm}$ to $10^{\wedge} 15 \mathrm{Nm}$. We found a less rapid decrease of corner frequency with increasing seismic moment than expected from selfsimilar scaling considerations, as can be seen in Figure 10a. This behavior may be considered as an evidence for a break in self similarity scaling as reported in some studies [Malagnini et al. 2008, Mayeda et al. 2007, Mayeda 2009, 2010] though the magnitude range of our data $\left(\mathrm{M}_{\mathrm{L}}\right.$ 1.5-4.4) with the vast majority of earthquakes (about 90 percent) with $\mathrm{M}_{\mathrm{L}} 1.5-3$ is fairly limited to allow us to deduce a firm conclusion about non self-similar scaling.

The evaluated stress drops range from about 0.04 to $5.2 \mathrm{MPa}$, with an average of $0.9 \mathrm{MPa}$ (Figure 10b). These values are close to the stress drops reported by Hamzehloo et al. [2010] for three events of the Silakhor earthquake that are not included in our database. They obtained a stress drop value of 4.3 $\mathrm{MPa}$ for the mainshock $\left(\mathrm{M}_{\mathrm{W}}\right.$ 6.1) and 3.2 $\mathrm{MPa}$ and 2.8 $\mathrm{MPa}$ for the selected foreshock and largest aftershock with $\mathrm{M}_{\mathrm{W}}=5.1$ and 4.9 , respectively.

The obtained apparent stresses range from about 0.016 to $2.5 \mathrm{MPa}$, with an average of $0.2 \mathrm{MPa}$. A comparison of the evaluated apparent stress and stress drop values is represented in Figure 11. The solid line indicates the theoretical ratio of $\Delta \sigma / \sigma_{\mathrm{a}}=4.3$ [Singh and Ordaz 1994]. Considering the errors in Figure 11, the relation between estimated apparent stress and stress drop values is approximately consistent with the theoretically expected relation.

The comparison of estimated $\mathrm{M}_{\mathrm{W}}$ versus local magnitude $M_{L}$ is depicted in Figure 12. The moment magnitude $\mathrm{M}_{\mathrm{W}}$ and the local magnitude $\mathrm{M}_{\mathrm{L}}$ are linearly correlated. The local magnitude $\mathrm{M}_{\mathrm{L}}$ generally underestimates $\mathrm{M}_{\mathrm{W}}$ by about 0.1 - 0.5 magnitude units for $\mathrm{M}_{\mathrm{W}}$ 1.5-3.0 and larger events have approximately the same $M_{W}$ and $M_{L}$. The relation between the estimated moment magnitudes $\mathrm{M}_{\mathrm{W}}$ and local magnitude $\mathrm{M}_{\mathrm{L}}$ can be expressed using least squares regression as follows

$$
\mathrm{M}_{\mathrm{w}}=(0.68 \pm 0.03) \mathrm{M}_{\mathrm{L}}+(0.91 \pm 0.07)
$$

There are only a few studies that have investigated magnitude conversion relations for Iran [Shahvar et al. 2013, Zare et al. 2014, Shoja-Taheri et al. 2007]. Considering the magnitude range of events, to our knowledge this study is the first one looking at the relation between $M_{W}$ and $M_{L}$ within the magnitude 
range $M_{L}$ 1.5-4.4 in Iran and is in good agreement with previous studies in Iran that investigated different magnitude ranges [e.g. Shahvar et al. 2013 and Zare et al. 2014 relationships that are shown in Figure 12].
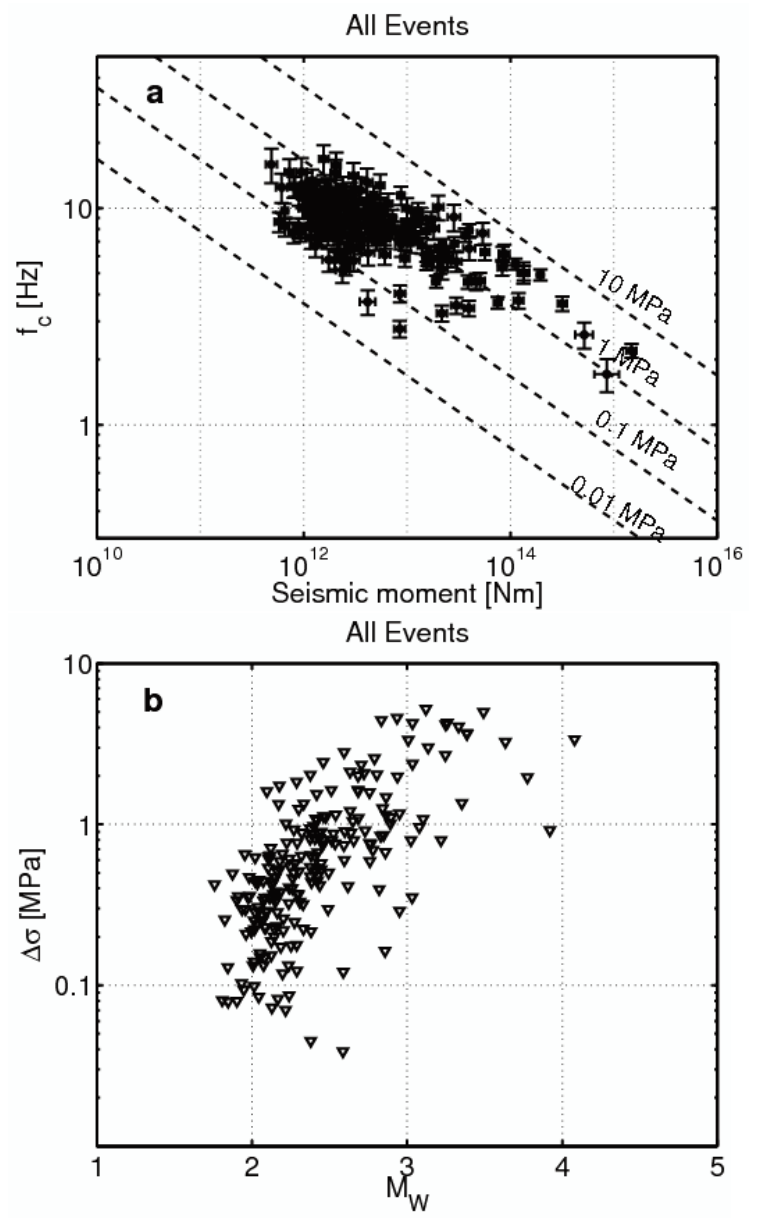

Figure 10. (a) Corner frequency versus seismic moment plot with constant stress drop values indicated by dashed lines. (b) Stress drop versus moment magnitude. Stress drop values range from 0.04 to $5.2 \mathrm{MPa}$.

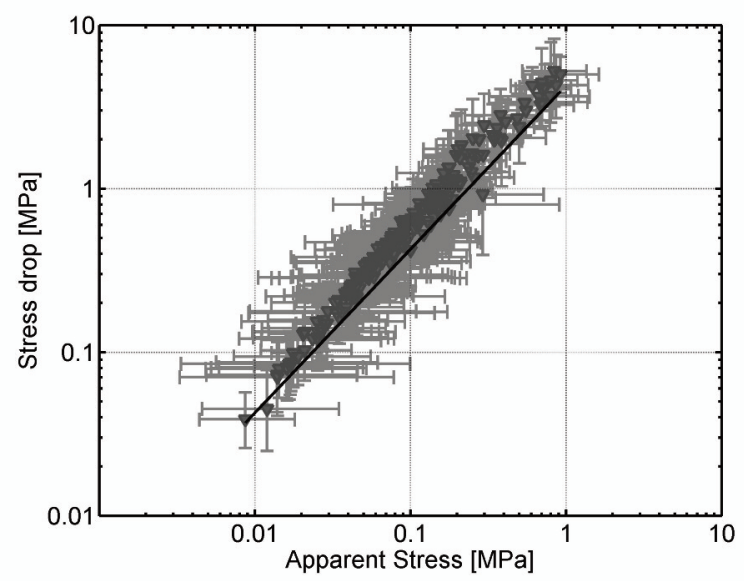

Figure 11. Stress drop versus apparent stress with error bars. The theoretical relation is indicated by solid line.

\subsection{Site Response}

The GIT site amplification terms have been derived for both horizontal $(\mathrm{H})$ and vertical component

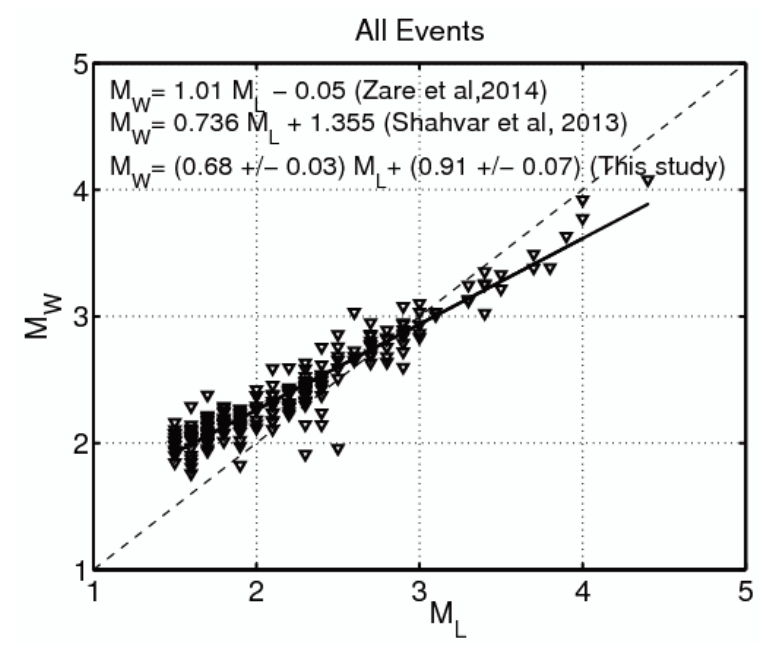

Figure 12. Local magnitude $M_{L}$ versus moment magnitude $M_{W}$ estimated from source spectral fitting. The solid line shows the best least squares fit. The dashed line indicates a one-to-one scaling.

(Z) data for all stations. We performed the GIT inversion for the vertical $(Z)$ component applying the same $S$-wave windows and reference condition as the horizontal $(\mathrm{H})$ component to investigate the $Z$ component amplification effect. We provide a comparison between the GIT site response functions and the horizontal to vertical $(\mathrm{H} / \mathrm{V})$ spectral ratios calculated directly from the observed spectra. The H/V method was first applied by Lermo and Chavez-Garcia (1993) to the Swaves of earthquake recordings to evaluate site effects. This technique assumes that the vertical component of the ground motion is not considerably affected by the local site conditions.

Figure 13 depicts the evaluated GIT site amplification function ratio of the horizontal and vertical components (GIT H/Z) (solid line) and the H/V spectral ratios (dashed line) as well as the individual GIT amplification curves for horizontal (GIT H) and vertical (GIT Z) components for all stations. As previously mentioned we considered stations GOSH and VANA as reference constraint for which the $\mathrm{H} / \mathrm{V}$ spectral ratios are reasonably flat and near to one over the entire frequency range of analysis (as can be seen from the Figure 13). The amplification functions are generally well constrained with small standard deviations obtained from the bootstrap analysis indicated in the GIT H curves as gray shaded areas with the maximum amplification of about 20 with respect to the reference sites.

Overall the observed GIT H/Z and H/V curves are similar with small discrepancies. These small variations most probably originate from the differences in the reference site's amplification function, as we set the average response functions of stations GOSH and VANA to 1 for GIT method though it is not exactly one and slightly larger than unity for $\mathrm{H} / \mathrm{V}$ case. Therefore $\mathrm{H} / \mathrm{V}$ ratios underestimate the GIT $H / Z$ results in most cases. 

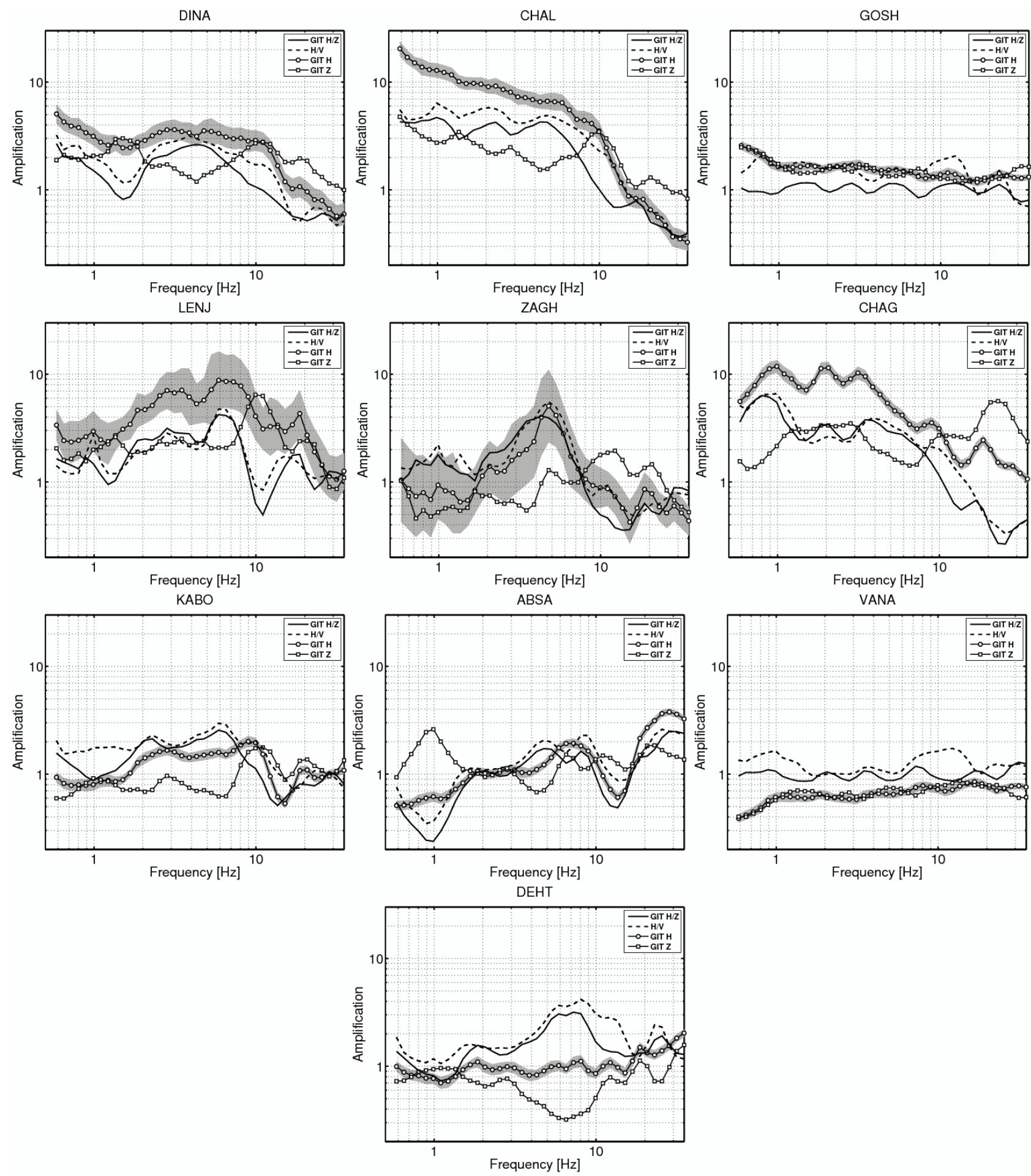

Figure 13. Site amplification functions resulting from the GIT in comparison with H/V spectral ratios (dashed lines) directly calculated from the observed ground-motion spectra for all stations. The GIT H/Z (solid lines) denotes the GIT site response of $\mathrm{H}$ component divided by GIT site response of $Z$. The individual GIT site response functions for horizontal (solid lines with circles) and vertical (solid lines with squares) components are also indicated. The gray shaded areas mark the mean \pm one standard deviation from 100 bootstrap analyses for the GIT H site responses.

The largest amplification based on GIT H/Z is observed at station CHAG with a factor of 7 with peak near $1 \mathrm{~Hz}$. The amplification peaks almost range from 1 to about $8 \mathrm{~Hz}$ for the majority of stations.

The GIT H/Z and H/V site functions represent significant differences with GIT H curves in the level of amplification. These differences are due to amplifica- tion of vertical component as can be seen for instance at stations LENJ and CHAG at frequencies 10 and 25 $\mathrm{Hz}$ respectively. Based on geological maps the five stations (i.e. VANA, DINA, GOSH, DEHT and KABO) are deployed on bedrock, for which the trends of the GIT $\mathrm{H}$ and $\mathrm{H} / \mathrm{V}$ ratio are most consistent. The small differences between these stations in the high frequency 
range are most probably due to the complex geological setting (e.g. sedimentary rocks; dolomite limestone and igneous rocks; granite and grano-diorite) around stations. The remaining stations (i.e. ABSA, CHAL, LENJ, ZAGH and CHAG) are mostly placed on a thin layer of quaternary alluvium. The observed decrease in the ratio of $\mathrm{H} / \mathrm{V}$ and GIT $\mathrm{H} / \mathrm{Z}$ caused by amplification of vertical component in the high frequency range at stations CHAG, LENJ and ZAGH is most probably due to a sharp contrast interface in this area and can be related to S-P conversions at the bottom of the soft layer in the case of high-impedance contrasts as Parolai and Richwalski [2004] discussed.

\section{Discussion and conclusions}

We applied the Generalized Inversion Technique (GIT) to the data recorded by 10 temporary stations installed around the epicenter of 2006 Silakhor earthquake for 2 months. We investigated the source parameters, attenuation characteristics and site response functions using the non-parametric one step GIT to the observed spectral amplitudes of 213 events within the magnitude range $M_{L}$ 1.5-4.4.

The attenuation curves decay monotonically with distance for the entire frequency range with a more rapid decay for the high frequency attenuation curves than the low frequency ones.

The attenuation is almost consistent with $1 / \mathrm{R}$ decay function for the low frequency curves up to about $20 \mathrm{Km}$ however beyond this distance the curves attenuate more quickly than $1 / \mathrm{R}$ for all frequency range.

A comparison of the obtained apparent quality factor in this study with other studies for Iran is described in Figure 14 (see also Table 1). Hamzehloo et al. [2010] applied the SH-wave acceleration spectral data of the 2006 Silakhor earthquake and only one of its foreshock and aftershock to estimate the shear wave quality factor, $Q_{S}(f)=121 f^{0.55}$ in the six selected frequency bands from 1 to $24 \mathrm{~Hz}$. Hassani et al. (2011) estimated the $S$-wave quality factor as $Q_{S}(f)=151 f^{0.75}$ using GIT with a dataset consisting of 40 earthquakes recorded in East-Central Iran for the frequency range 0.4-15 Hz. Farrokhi and Hamzehloo (2016) investigated the attenuation of $\mathrm{P}$ and $\mathrm{S}$ waves in Alborz and north central part of Iran. They applied the extended coda normalization method (CNM) for 380 local earthquakes in the seven frequency bands between 0.4 to $24 \mathrm{~Hz}$ to define $Q_{S}(f)=83 f^{0.99}$ and $Q_{S}(f)=68 f^{0.96}$ in Alborz region and North Central Iran, respectively. Another quality factor relation in North of Iran is reported by Motazedian [2006] as $Q_{S}(f)=87 f^{1.46}$ based on the vertical component of 22 earthquakes. The es- timated $S$ wave quality factor in our study shows fairly strong frequency dependence and high attenuation in seismically active region of Zagros which is compatible with results reported for other parts of Iran. However, considering slight differences between these relations, it should be noted that in these studies different methods have been applied to obtain quality factors implementing various geometrical spreading functions in different frequency ranges sampling different crustal volumes. Furthermore, the study areas of these models are different (except Hamzehloo et al., 2010) and each relation is linked to various seismotectonic provinces of Iran with distinct seismotectonic characteristics [e.g. Mirzaei et al. 1998].

The inverted source spectra were fitted by the omega square source model satisfactorily to retrieve earthquake source parameters. The inferred corner frequencies are ranging between about 1 and $17 \mathrm{~Hz}$ spanning within 4 orders of magnitude. We found a less rapid decrease of corner frequency with increas-

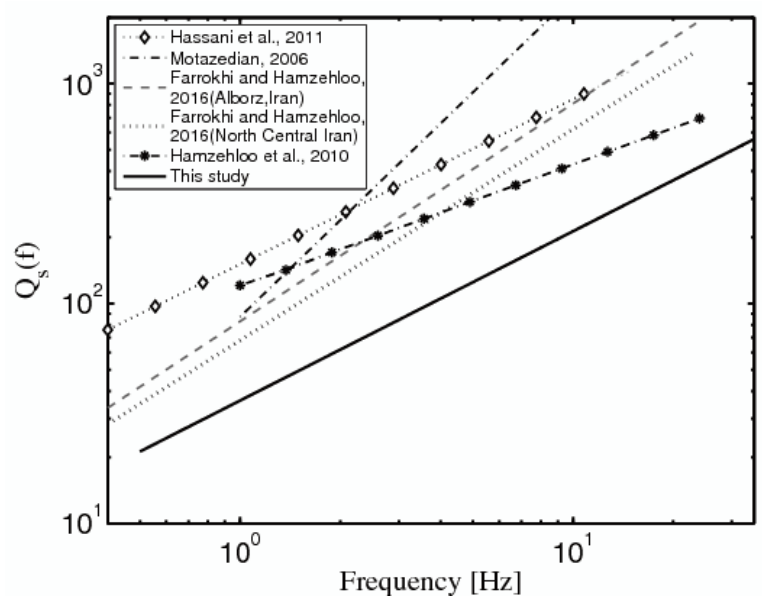

Figure 14. The comparison of the $\mathrm{Q}_{S}(\mathrm{f})$ estimated in this study (solid black line) with other studies for Iran.

ing seismic moment than expected from self-similar scaling considerations. This result can be considered as an evidence for a break in self-similar scaling, however bearing in mind the small magnitude range of this study $\left(\mathrm{M}_{\mathrm{L}}\right.$ 1.5-4.4) including the vast majority of earthquakes with $\mathrm{M}_{\mathrm{L}}$ 1.5-3 (about 90 percent), more work is needed to derive a definitive conclusion about non self-similarity in this sequence.

The estimated stress drop values range between 0.04 and 5.2 MPa with an average of $0.9 \mathrm{MPa}$. The obtained rather low stress drops are near the lower limit of the typical worldwide observations $[\sim 0.1-100$, e.g., Kanamori 1994]. The values are however in the same range as observed for crustal earthquakes in Japan [Oth 2013] and are in agreement with the expected smaller stress drops for interplate earthquakes (such 


\begin{tabular}{|c|c|c|c|c|}
\hline Region & Frequency range $(\mathrm{Hz})$ & Quality factor & Geometrical spreading & Reference \\
\hline Zagros region & $\begin{array}{l}\text { Six frequency bands } \\
\text { between } 1 \leq \mathrm{f} \leq 24\end{array}$ & $Q_{S}(f)=121 f^{0.55}$ & $\mathrm{R}^{-1}$ & Hamzehloo et al. [2010] \\
\hline East-Central of Iran & $0.4 \leq \mathrm{f} \leq 15$ & $Q_{S}(f)=151 f^{0.75}$ & $\begin{array}{ll}\mathrm{R}^{-1}, & \mathrm{R}<60 \\
(60 \mathrm{R})^{-0.5}, & \mathrm{R} \geq 60\end{array}$ & Hassani et al. [2011] \\
\hline $\begin{array}{l}\text { Alborz region } \\
\text { North Central Iran }\end{array}$ & $\begin{array}{l}\text { Seven frequency bands } \\
\text { between } 0.4 \leq \mathrm{f} \leq 24\end{array}$ & $\begin{array}{l}Q_{S}(f)=83 f^{0.99} \\
Q_{S}(f)=68 f^{0.96}\end{array}$ & $\begin{array}{ll}\mathrm{R}^{-1}, & \mathrm{R}<90 \\
(90 \mathrm{R})^{-0.5}, & \mathrm{R} \geq 90\end{array}$ & $\begin{array}{l}\text { Farrokhi and Hamzehloo. } \\
\text { [2016] }\end{array}$ \\
\hline North of Iran & $1<\mathrm{f} \leq 10$ & $Q_{S}(f)=87 f^{1.46}$ & $\begin{array}{c}\mathrm{R}^{-0.6}, \quad \mathrm{R}<70 \\
\mathrm{R}^{0.2}, \quad 70 \leq \mathrm{R} \leq 150 \\
\mathrm{R}^{-0.1}, \mathrm{R}>150\end{array}$ & Motazedian. [2006] \\
\hline Zagros region & $0.5 \leq \mathrm{f} \leq 35$ & $Q_{S}(f)=36 f^{0.77}$ & $\mathrm{R}^{-1}$ & This study \\
\hline
\end{tabular}

Table 1. S-wave attenuation models reported for Iran.

as Silakour events within tectonically active Zagros area) compared to higher stress drop values observed for intraplate events [e.g., Allmann and Shearer 2009].

Our estimated stress drop values were compared with the evaluated apparent stresses. The relation between these two parameters is generally consistent with the theoretically expected relation assuming Brune model.

Comparison of evaluated $\mathrm{M}_{\mathrm{W}}$ versus local magnitude $M_{L}$ indicates that the local magnitude $M_{L}$ generally underestimates the moment magnitude $\mathrm{M}_{\mathrm{W}}$ in the order of 0.1-0.5 magnitude units. This result is in good agreement with previous studies in Iran [e.g. Shahvar et al. 2013 and Zare et al. 2014]. Considering the magnitude range of events, our study is the first one that investigated the relation between $\mathrm{M}_{\mathrm{W}}$ and $M_{L}$ within the magnitude range $M_{L}$ 1.5-4.4 in Iran.

To investigate the influence of kappa parameter on the source spectra, this parameter was estimated from the high-frequency part of the spectra. The evaluated $\kappa$ values with small mean value of $0.011 \mathrm{sec}$ indicate the attenuation corrected spectra are subjected to small high frequency diminution effect.

The results of site amplification functions obtained from GIT, represent the amplification peaks, almost range from 1 to about $8 \mathrm{~Hz}$ for the majority of stations with the maximum amplification of about 20 with respect to the reference sites. The different site responses for stations depend on the geological situation beneath the seismic stations, individually. Some stations are not strongly affected by amplification effects and are supposed to be located on rock. The provided GIT $Z$ site responses for the vertical components present considerable amplifications leading to reduction in the $\mathrm{H} / \mathrm{V}$ amplitude in comparison with the GIT H amplification functions. However, the overall shape of site spectra estimated by both methods is almost similar.

Finally, the results of our study including the re- gion-specific source, attenuation functions and site responses provide important elements for further strong motion simulations and seismic hazard assessment.

Acknowledgements. The authors acknowledge International Institute of Earthquake Engineering and Seismology (IIEES) for providing earthquake waveform database used in this study. This research was performed during the 7 months visit of S. Ahmadzadeh at the German Research Centre for Geosciences (GFZ) in Potsdam that was partially funded by the GFZ. We also appreciate the anonymous reviewers which their comments and suggestions improved our paper.

\section{References}

Allmann, B. P. and P. M. Shearer (2009). Global variations of stress drop for moderate to large earthquakes, J. Geophys. Res., 114, B01310, doi:10.1029/2008JB005821.

Ambraseys, N. N. and C.P. Melville (1982). A History of Persian Earthquakes, Cambridge Univ. Press, Cambridge, 219 pp.

Anderson, J. G. and S. E. Hough (1984). A model for the shape of the Fourier amplitude spectrum of acceleration at high frequencies, Bull. Seism. Soc. Am.,74(5), 1969-1993.

Andrews, D. J. (1986). Objective determination of source parameters and similarity of earthquakes of different size, in Earthquake Source Mechanics, edited by S. Das, J. Boatwright, and C. H. Scholz, pp. 259-268, AGU, Washington, D. C.

Bindi, D., S. Parolai, H. Grosser, C. Milkereit, and S. Karakisa (2006). Crustal attenuation characteristics in northwestern Turkey in the range from 1 to 10 Hz, Bull. Seism. Soc. Am., 96, 200-214.

Boatwright, J., J. Fletcher, and T. Fumal (1991). A general inversion scheme for source, site, and propagation characteristics using multiply recorded sets of moderate-sized earthquakes, Bull. Seism. Soc. Am., 81, 1764-1782. 
Brune, J. N. (1970). Tectonic stress and the spectra of seismic shear waves from earthquakes, J. Geophys. Res., 75, 4997-5009.

Brune, J. N. (1971). Correction, J. Geophys. Res., 76, 5002.

Castro, R. R., J. G. Anderson, and S. K. Singh (1990). Site response, attenuation and source spectra of $S$ waves along the Guerrero, Me'xico, subduction zone, Bull. Seism. Soc. Am., 80, 1481 - 1503.

Castro, R. R., F. Pacor, A. Sala, and C. Petrungaro (1996). S wave attenuation and site effects in the region of Friuli, Italy, J. Geophys. Res., 101, 2235522369.

Dutta, U., N. Biswas, A. Martirosyan, A. Papageorgiou, and S. Kinoshita(2003). Estimation of earthquake source parameters and site response in Anchorage, Alaska from strong-motion network data using generalized inversion method. Phys. Earth Planet. Inter., 137, 13-29.

Efron, B. (1979). Bootstrap methods, another look at the jacknife, Ann. Stat., 7, 1-26.

Farrokhi, M. and H. Hamzehloo (2016). Body wave attenuation characteristics in the crust of Alborz region and North Central Iran, J. Seismol., doi:10.1007/s10950-016-9624-2.

Ghods, A., M. Rezapour, E. Bergman, G. Mortezanejad, and M. Talebian (2012). Relocation of the 2006 $M_{w} 6.1$ Silakhour, Iran, earthquake sequence: Details of fault segmentation on the main recent fault, Bull. Seism. Soc. Am., 102(1), 398-416.

Hamzehloo, H., H. Rahimi, I. Sarkar, M. Mahood, H. MirzaeiAlavijeh, and E. Farzanegan (2010). Modeling the strong ground motion and rupture characteristics of the March 31, 2006, Darb-e-Astane earthquake, Iran, using a hybrid of near-field SHwave and empirical Green's function method, J. Seismol., 14, 169-195.

Hartzell, S. H. (1992). Site response estimation from earthquake data, Bull. Seism. Soc. Am., 82, 2308 2327.

Hassani, B., H. Zafarani,J. Farjoodi, and A. Ansari (2011). Estimation of site amplification, attenuation and source spectra of S-waves in the East-Central Iran, Soil Dyn Earthq Eng 31, 1397-1413.

Hellweg, M., P. Spandich, J. B. Fletcher, and L. M. Baker (1995). Stability of coda Q in the region of Parkfield, California: view from the U.S. Geological survey Parkfield dense seismograph array, J. Geopys. Res., 100, 2089-2102.

Havskov, J. and L. Ottemoller (1999). SeisAn earthquake analysis software, Seismological Research Letters, 70, 5, 532-534.
Kanamori, H. (1994). Mechanics of earthquakes, Annu Rev Earth Planet Sci., 22, 207-237.

Konno, K., and T. Ohmachi (1998). Ground-motion characteristics estimated from spectral ratio between horizontal and vertical components of microtremors, Bull. Seism. Soc. Am., 88, 1228-1241.

Lermo, J. and F. J. Cha'vez-Garci'a (1993). Site effect evaluation using spectral ratios with only one station, Bull. Seism. Soc. Am., 83, 1574-1594.

Malagnini, L., L. Scognamiglio, A. Mercuri, A. Akinci, and K. Mayeda (2008). Strong evidence for non-similar earthquake source scaling in central Italy, Geophys. Res. Lett., 35, L17303.

Mayeda, K., L. Malagnini, and W. R. Walter (2007). A new spectral ratio method using narrow band coda envelopes: Evidence for non-self-similarity in the Hector Mine sequence, Geophys. Res. Lett., 34, L11303.

Mayeda, K., and L. Malagnini (2009). Apparent stress and corner frequency variations in the 1999 Taiwan (Chi-Chi) sequence: evidence for a step-wise increase at $\mathrm{M}_{\mathrm{w}}<5.5$, Geophys. Res. Lett., 36, L10308.

Mayeda, K., and L. Malagnini (2010). Source radiation invariant property of local and near-regional shearwave coda: Application to source scaling for th $M_{w} 5.9$ Wells, Nevada sequence. Geophys. Res. Lett. 37, L07306.

Menke, W. (1989). Geophysical data analysis: discrete inverse theory, in Int. Geophys. Series, R. Dmowska and J. R. Holton (Series Editors), Vol. 45, Academic Press, New York, 289 pp.

Mirzaei, N., G. Mengtan and C, Yuntai (1998). Seismic source regionalization for seismic zoning of Iran: Major seismo tectonic provinces, J Earthquake Pred Res, 7, 465-95.

Moghadam, A. S., K. Hesami,G, Javan Doloei, M. Mahdavifar and H. Hamzehloo (2006). The 2006 Darb-eAstane earthquake field report. In: International institute of earthquake engineering and seismology, 233 p. (In Farsi).

Motazedian, D. (2006). Region-specific key seismic parameters for earthquakes in northern Iran. Bull. Seism. Soc. Am., 96, 1383-1395.

Oth, A., S. Parolai, D. Bindi and F. Wenzel (2009). Source spectra and site response from Swaves of intermediate-depth Vrancea, Romania, earthquakes, Bull. Seism. Soc. Am., 99, 235254.

Oth, A., D. Bindi, S. Parolai and D. Di Giacomo (2011). Spectral analysis of K-NET and KiK-net data in Japan, Part II: On attenuation characteristics, source spectra, and site response of borehole and surface stations. Bull. Seism. Soc. Am., 101, 667-687. 
Oth, A. (2013). On the characteristics of earthquake stress release variations in Japan, Earth Planet. Sci., 377-378, 132-141.

Paige, C. C. and M. A. Saunders (1982). LSQR: An algorithm for sparse linear equations and sparse least squares, ACM Trans. Math. Software 8, 43-71.

Parolai, S., D. Bindi and P. Augliera (2000). Application of the generalized inversion technique (GIT) to a microzonation study: numerical simulations and comparison with different site-estimation techniques. Bull. Seism. Soc. Am., 90, 286-297.

Parolai, S., and D. Bindi (2004). Influence of soil-layer properties on k evaluation, Bull. Seism. Soc. Am., 94, 349-356.

Parolai, S. and S. M. Richwalski (2004). The importance of converted waves in comparing $\mathrm{H} / \mathrm{V}$ and RSM site response estimates, Bull. Seism. Soc. Am., 94, 304-313.

Parolai, S., D. Bindi, M. Baumbach, H. Grosser, C. Milkereit, S. Karakisa and S. Zunbul (2004). Comparison of different site response estimation techniques using aftershocks of the 1999 Izmit earthquake, Bull. Seism. Soc. Am., 94, 1096.

Peyret, M., F. Rolandrone, S. Dominguez, Y. Djamour and B. Meyer (2008). Source model for the $\mathrm{M}_{\mathrm{w}} 6.1$, 31 March 2006, Chalan-Chulan earthquake (Iran) from InSAR, Terra Nova20, 126-133.

Rahimi, H. and H. Hamzehloo (2008). Lapse time and frequency-dependent attenuation of coda waves in the Zagros continental collision zone in Southwestern Iran, J. Geophys. Eng. 5, 173-185.

Rovelli, A., O. Bonamassa, M. Cocco, M. Di Bona and S. Mazza (1988). Scaling laws and spectral parameters of the ground motions in active extensional areas in Italy, Bull. Seism. Soc. Am., 78, 530-560.

Salazar, W., V. Sardina and J. de Cortina (2007). A hybrid inversion technique for the evaluation of source, path, and site effects employing S-wave spectra for subduction and upper-crustal earthquakes in El Salvador, Bull. Seism. Soc. Am., 97, 208-221.

Sepahvand, M. R., F. Yaminifard, M. Tatar and M. R. Abbassi (2012). Aftershocks study of the 2006 Silakhur earthquake (Zagros, Iran): seismological evidences for a pull-apart basin along the Main Recent Fault, Doroud segments, J. Seismol., 16, 233251.

Shahvar, M. P., M. Zare and S. Castellaro (2013). A unified seismic catalog for the Iranian plateau (1900 2011), Seismol. Res. Lett., 84, 233-249.

Sharma, B., K. A. Gupta, K. D. Devi, D. Kumar, S. S. Teotia and B. K. Rastogi (2008). Attenuation of high frequency seismic waves in Kachchh region, Gujarat, India, Bull. Seism. Soc. Am., 98, 23252340.

Shoja-Taheri, J., S. Nasserrieh, and H. Ghofrani (2007). $\mathrm{M}_{\mathrm{L}}$ and $\mathrm{M}_{\mathrm{W}}$ scales in the Iranian Plateau based on the strong-motion records, Bull. Seism. Soc. Am., 97,661-669.

Singh, S. K. and M. Ordaz (1994). Seismic energy release in Mexican subduction zone earthquakes, Bull. Seism. Soc. Am., 84, 1533-1550.

Tchalenko, J.S. and J. Braud (1974). Seismicity and structure of the Zagros (Iran): The Main Recent Fault between $33^{\circ}$ and $35^{\circ} \mathrm{N}$. Phil. Trans. R. Soc. London, 277, 1 -25.

Yoshimoto, K., H. Sato and M. Ohtake (1993). Frequency dependent attenuation of $\mathrm{P}$ and $\mathrm{S}$ waves in the Kanto area, Japan, based on the coda normalization method, Geophys. J. Int., 114, 165-174.

Zafarani H, and B. Hassani (2013). Site response and source spectra of S-waves in the Zagros region, Iran, J. Seismol., 17, 645-666.

Zare, M., H. Amini, P. Yazdi, K. Sesetyan, M.B. Demircioglu, D. Kalafat, M. Erdik, D. Giardini, M. Asif Khan and N. Tsereteli (2014). Recent developments of the Middle East catalog, J. Seismol., 18, 749-772.

\footnotetext{
*Corresponding author: Gholam Javan-Doloei, International Institute of Earthquake Engineering and Seismology, Tehran, Iran; email: Javandoloei@iiees.ac.ir.

(C) 2017 by the Istituto Nazionale di Geofisica e Vulcanologia. All rights reserved.
} 